\title{
The influence of non-verbal body language on sport performance in professional tennis
}

\author{
Rafael Martínez-Gallego a ${ }^{\text {(D) } ~ \& ~ D a v i d ~ C a r r i l l o ~ M o l i n a ~}$ \\ ${ }^{a}$ University of Valencia, Valencia, Spain.
}

\begin{abstract}
The main objective of this study was to analyse the relationship between players' nonverbal body language and their performance in sport. The sample consists of a total of 477 actions from 40 players competing in the ATP Tour. All actions were taken from tiebreaks in official tournaments. The categories that were analyzed were previous performance, dominant non-verbal body language, submissive non-verbal body language, and performance later on. Results show how the players' non verbal body language impacts on their performance later on. Thus, we can conclude that following dominant non-verbal body language, the probabilities of better performance in the next point are greater than following submissive non-verbal body language. Therefore, it is important to train these aspects as an extra tool to improve players' performance.
\end{abstract}

\author{
Key words: non verbal body \\ language, performance, tennis, \\ analysis. \\ Received: 14 November 2019 \\ Accepted: 10 December 2019 \\ Corresponding author: Rafael \\ Martínez-Gallego, Faculty of \\ Physical Activity and Sport \\ Sciences, University of \\ Valencia, Spain. Email: \\ ramargal@hotmail.com
}

\section{INTRODUCTION}

Body language or non verbal body language (NVB) had not been deeply studied until a few years ago, in spite of its importance for sport in general, and for tennis in particular. In fact, authors like Furley, Dicks \& Memmert (2012) state that it is surprising that until not long ago research had neglected the analysis of non-verbal body language in sporting contexts.

Motos (cited in Lara \& Moral, 2008) conclude that elementary communication takes place through verbal language, but body language relates with the latter, confirming or denying its message. He adds that between $50-65 \%$ of the information transmitted in a message is body coded. Thus, it confirms the existence and validation of a specialized non-verbal language in sport (Vallejo et al., 2004).

The main conclusions of relevant research in this area, expressing the importance of body language in sport, are presented below.

Lara \& Moral (2008) analysed communication through behaviour and the use of the body by 12 top level female volleyball players. The main conclusion drawn was that after winning a point, there is a feeling of joy, and it is not important to share it with the others, but, when losing a point there is a feeling which is closer to sadness and they prefer not to communicate it. Therefore, it has been demonstrated that there exists a kind of body language (non-verbal body language) when losing a point, and a different one when winning a point. These authors state that when the point is lost, players bow their heads with a passive expression in their faces and with asymmetric and closed body forms, in a way that usually expresses anger and rage which last for a short time since they quickly try to forget. On the contrary, when they win the point, their head position is up, the head is raised, the trunk is erect and open and symmetrical body forms express joy. Energetic, quick and intense movements last longer. Finally, these authors come to the relevant conclusion that most of the time, this body language is unconscious (communication and expression through body and movement).

Accordng to Buscombe, Greenlees, Holder, Thelwell \& Rimmer (2006), tennis players cause initial impressions on their opponents during warm-up on the bases of their opponent's body language, which impacts on their level of confidence.

On the other hand, Furley et al. (2012) analysed body language in football penalty shots and came to the conclusion that goal keepers had a more positive impression than those players whose body language is submissive, that is to say, they were more confident on the possibilities of stopping the penalty against players whose body language was meek, compared to players whose body language was dominant. 
Furley y Dicks (2012) in their research with amateur baseball players in Germany concluded that athletes should be advised to avoid expressing or showing submissive body language, since it can instil confidence in the opponent, and therefore give them a sporting performance.

Greenlees, Buscombe, Thelwell, Holder \& Rimmer (2005) analysed the impact of body language, watching videos in which tennis players were warming up. Their main conclusion was that tennis players expect a better performance against those whose body language is negative, in contrast to those whose body language is positive.

This research also concludes that athletes can gain an advantage over their opponents by using an appropriate body language. Therefore, coaches and sport psychologists should develop techniques to improve athletes' body language.

It should be noted that body language analysis is closely related to sport performance. In spite of this, there is very little information regarding elite tennis. Thus, this study analyses the relationship between body language between points and its relationship with the performance in the previous and the following points.

\section{METHOD}

Sample:

The sample consists of 477 actions from 40 ATP Tour players, who, at the time of the research were ranked between 1 and 382 in the ATP Tour. All actions were taken from tie-breaks in official tournaments between 2010 and 2018 .

Variables analyzed:

The variables analyzed were classified into five categories, and in each category we identified more specific actions or behaviours. These categories and actions are:

- Dominant NVB: upright with good posture, head up and $90 \%$ of the time looking at the opponent.

- Submissive NVB: hunched posture, shrunken body, shoulders forward and eyes looking down.

- PRE-Performance: good own action, good opponent action, bad own action, bad opponent action and performance does not change.

- POST-Performance: good own action, good opponent action, bad own action, bad opponent action and performance does not change.

\section{Statistical analysis:}

The statistical analysis was performed using SPSS statistic pack, version 21. The Kolmogorov Smirnov test was performed to test the normality of data in each variable, and in all variables a significance level of less than 0.05 was obtained which indicates that the distribution was not normal, therefore, we used non-parametric tests. The Chi squared test was conducted, in order to investigate if a relationship existed between the different variables analyzed, and to check if there were significant differences in these variables.

\section{FINDINGS AND DISCUSSION}

\section{Predominant NVB}

The predominant NVB in top tennis competition is submissive, representing $56.71 \%$ of the total actions analysed, while the dominant represents $43.29 \%$ of all actions.

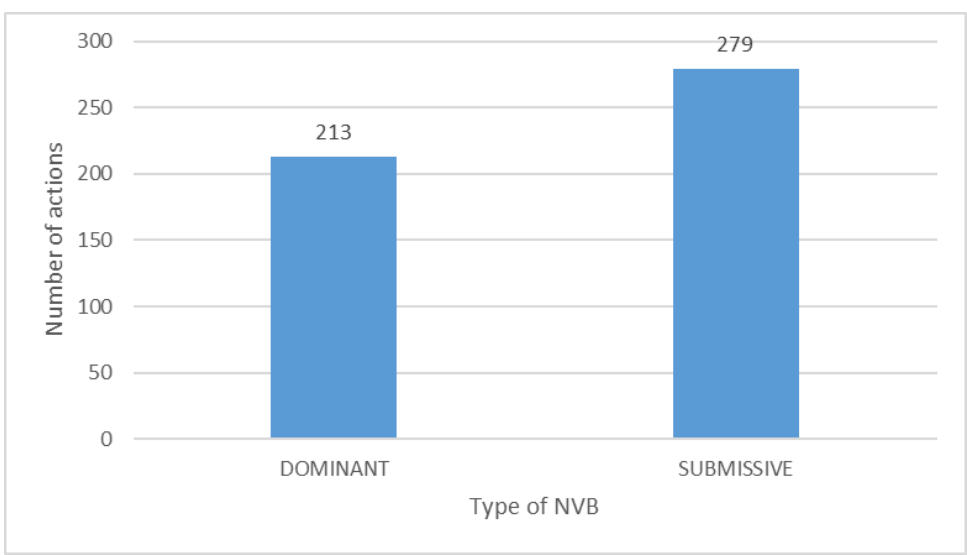

Figure 1. Frequency of dominant and submissive NVB

Relationship between previous performance and non-verbal body language of players

With regard to the relationship between the previous performance and the non-verbal body language type, Table 1 shows that there is no relationship between performance in the previous point, either succeeding (good own action) or failing (bad own action) ( $p>0.05)$, and the non-verbal body language or body language that will be expressed later, once the action is finished. Therefore, it is possible to conclude that previous performance does not impact on the body language of professional players.

Table 1.Relationship between pre-performance actions and NVB variables.

$\begin{array}{lll}\text { Positive action } & 62.9 \% & 66.34 \% \\ \text { Negative action } & 37.1 \% & 33.66 \%\end{array}$

$\chi^{2}=0,293 ; p=0,588$ 
Relationship between post-performance and non-verbal body language of the players

As Table 2 shows, there is a correlation between the postperformance and non-verbal body language $(p<0,05)$. This means that verbal language has a clear impact on the postperformance of the player. Therefore, given a submissive NVB, there will be a greater probability of negative performance and vice versa.

Table 2. Relationship between Post performance and NVB variables.

\begin{tabular}{lll}
\hline & $\begin{array}{l}\text { Submissive } \\
\text { NVB }\end{array}$ & Dominant NVB \\
\hline $\begin{array}{lll}\text { Positive action } \\
\text { Negative }\end{array}$ & $46.3 \%$ & $53.7 \%$ \\
\hline $\begin{array}{l}\text { action } \\
\chi^{2}=73,27 ; p<0,001\end{array}$ & $12.1 \%$ \\
\hline
\end{tabular}

\section{CONCLUSIONS}

No relationship has been found between previous performance and non verbal body language (NVB).

There is a relationship between non-verbal body language and post-performance. When there is a show of submissive NVB, it is followed by a greater number of negative actions later, but when there is a show of dominant NVB, , it is followed by a greater number of positive actions.

\section{COACHING IMPLICATIONS}

Given the aforementioned conclusions, the following plan for coaching dominant NVB is proposed in order to foster dominant verbal behaviours that favour enhanced sport performance.

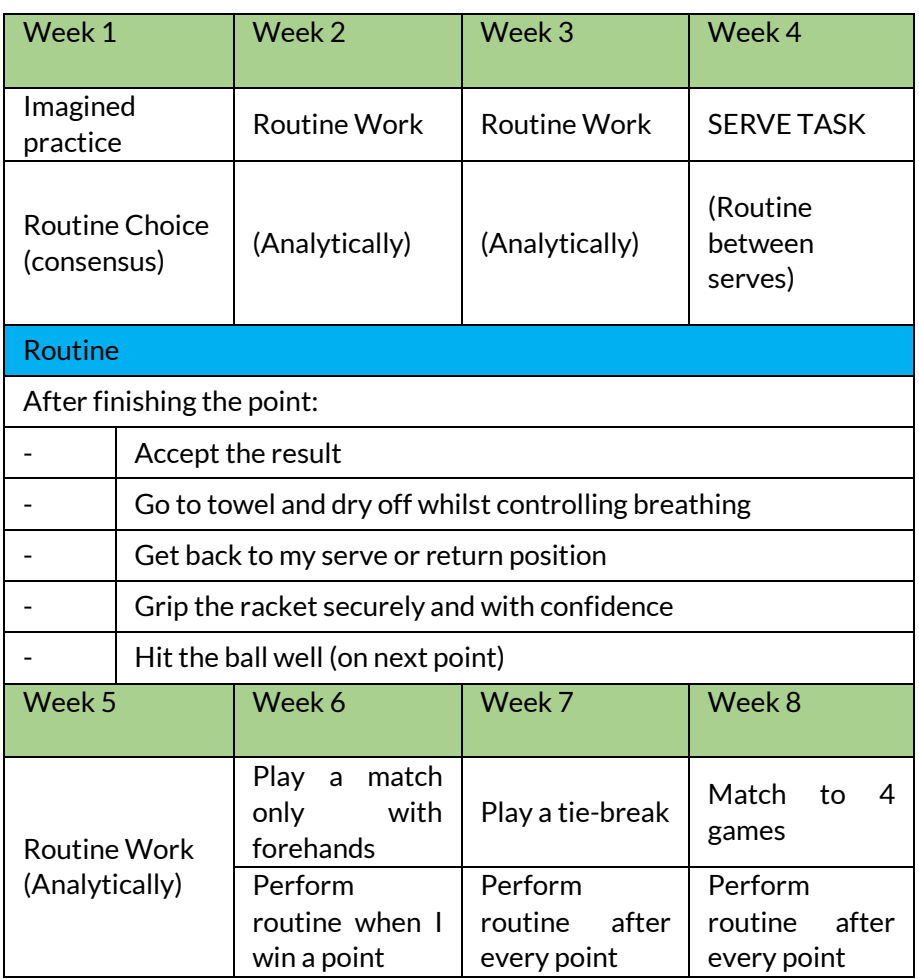

Table 3. Summary of the Dominant NVB coaching proposal

Table 3 shows the breakdown of the NVB coaching plan. There is a progression over time, beginning with more analytical work routines and ending up introducing routines in coaching work, that is to say, more global work, i.e. match routines. The length of the coaching proposal is two months, putting aside 20 minutes per day, three days a week, during coaching sessions.

\section{REFERENCES}

Buscombe, R., Greenlees, I., Holder, T., Thelwell, R., \& Rimmer, M. (2006). Expectancy effects in tennis: The impact of opponents' pre-match non-verbal behaviour on male tennis players. Journal of sports sciences, 24(12), 1265-1272,

https://doi.org/10.1080/02640410600598281

Furley, P., Dicks, M., \& Memmert, D. (2012). Nonverbal behavior in soccer: The influence of dominant and submissive body language on the impression formation and expectancy of success of soccer players. Journal of Sport and Exercise Psychology, 34(1), 61-82, https://doi.org/10.1123/jsep.34.1.61

Furley, P., \& Schweizer, G. (2016). Nonverbal communication of confidence in soccer referees: an experimental test of Darwin's leakage hypothesis. Journal of Sport and Exercise Psychology, 38(6), 590-597, https://doi.org/10.1123/jsep.2016-0192

Greenlees, I., Buscombe, R., Thelwell, R., Holder, T., \& Rimmer, M. (2005). Impact of opponents' clothing and body language on impression formation and outcome expectations. Journal of Sport and Exercise Psychology, 27(1), 39-52, https://doi.org/10.1123/jsep.27.1.39 
Lara, A., \& Moral, J. (2008). La expresión de las emociones de los deportistas mediante el lenguaje corporal. Int Med Sci Phys Educ Sport, 4.

Vallejo, G. C., Plested, M. C., \& Zapata, G. (2004). La comunicación no verbal en el nado sincronizado. Educación Física y Deporte, 23(2), 79-95.

RECOMMENDED ITF TENNIS ACADEMY CONTENT (CLICK BELOW)

\section{ITF Academy}

Copyright (c) 2019 Rafael Martínez-Gallego \& David Carrillo Molina

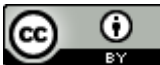

This text is under a Creative Commons BY 4.0 license

You are free to Share - copy and redistribute the material in any medium or format - and Adapt the content - remix, transform, and build upon the material for any purpose, even commercially under the following terms:

Attribution: You must give appropriate credit, provide a link to the license, and indicate if changes were made. You may do so in any reasonable manner, but not in any way that suggests the licensor endorses you or your use.

CCBY 4.0 license terms summary CCBY4.0 license terms 